\title{
Car Inside Beam Enhanced Cold Stamping Mould Design
}

\author{
Quanzhong Jia \\ Weifang University of Science \& Technology, Shandong, Shouguang, 262700, China.
}

Keywords: Stamping; Drawing die; Main structure; Design; Mold.

\begin{abstract}
This paper is on the study of cold stamping drawing die of a vehicle inner beam enhanced. Firstly, it determines the stamping parts process plan. Then it draws the die design, including the design of the main structure of the mold design and mold auxiliary parts. Finally, it analyzes the die working principle and carries on the summary to this design.
\end{abstract}

\section{Introduction}

Cold stamping is the use of the press on the die to put pressure on the material, so that it produces separation or plastic deformation, thereby obtains a pressure on the required parts of the processing method. It is an advanced metal processing method, which is one of the most basic and most important methods for metal forming. Compared with other methods of mechanical processing, this processing method has good product performance, high productivity, high material utilization rate, low cost, stable dimensional accuracy of the products, simple operation, good interchangeability and being easy to implement mechanization and automation, etc..

\section{The process analysis and the determination of stamping process plan for the stamping parts}

Mold CAE technology is in the design and manufacture of molds, in the computer simulated stamping parts in the mold forming process, users are informed of the die structure design and process conditions which are reasonable, which ultimately for users provide optimal mould design process, reliable reached more than $80 \%$.

Stamping parts feature. The part is a model of the inside of a reinforced plate. Material thickness of SPCC is $1.6 \mathrm{~mm}$. Processing is mass production in $20000 \mathrm{KN}$ oil press. After forming, the surface is smooth without warping, wrinkles or cracks. In the actual production, combined with the extension of geometry, it is accuracy and forming characteristics of the situation, according to the parts of the lost wrinkling and mechanical mechanism and drawing conditions on loss of wrinkling and other factors, from the panel structure, forming process and die design of the corresponding measures for avoiding wrinkle.

Determination of optimum stamping process plan. Through the parts analysis, due to a vehicle inner side member to strengthen in general, it is a more complex shape part. Compared with other drawing parts, the main difference is that the top of the curved surface is wavy, but pull a shallow, which can be formed by a deep drawing forming, without considering the crack phenomenon in the process of drawing. Behind the process, it is more complex, so in determining the parts process, considering the belongs to exterior parts, surface quality requirements is higher, the final solution is:

Blanking - forming - punching - cutting edge - plastic

\section{Drawing dies design}

Design of die structure. Determination of mold centre.

The design drawing pieces of sheet metal on the geometric center and the center of pressure is in the $\mathrm{X}$ direction consistent, $\mathrm{Y}$ direction of the eccentric is $7 \mathrm{~mm}$, small amount of eccentric, mould center can and drawing pressure coincident with the center; pressure mandril Y direction spacing is $125 \mathrm{~mm}$, the width of the plate material is $820 \mathrm{~mm}$, Y direction is arranged adjacent two rows of push rod is 
appropriate, mold and press centers in Y direction eccentricity for top bar spacing, half of which is $62.5 \mathrm{~mm}$. The distance between the top rod is $125 \mathrm{~mm}$ direction is $\mathrm{X}$, the material length is $980 \mathrm{~mm}$, the direction of $\mathrm{X}$ is appropriate, the center of the mould and the center of the press is coincident in $\mathrm{X}$ direction. The number of production of the top rod is 12 .

Determine the mold pressing surface size.

Binder size than the size of the sheet material, so as to ensure that the binder can press the whole sheet. The design of binder surfaces than the sheet size of the unilateral $10 \mathrm{~mm}$. Is binder length $1340 \mathrm{~mm}$ width $690 \mathrm{~mm}$, length direction with the center line of the mold for sy mmetry, width direction pressure burden and the mold center line offset $7 \mathrm{~mm}$.

The design of the pressure ring.

At work, the pressure side ring is subjected to a large load, and the pressure side ring should have a certain thickness to meet the strength and rigidity. While taking into account the guide space, reduce the balance block height, along the binder surface shape casting, pressure is low with burden of $20 \mathrm{~mm}$, the design pressure holder height is $280-448 \mathrm{~mm}$.

According to the binder unilateral widening of $150200 \mathrm{~mm}$, pressure ring edge length is $1340 \mathrm{~mm}$ and width is $690 \mathrm{~mm}$ which is the pressure ring edge width, and the weight is about $1200 \mathrm{~kg}$. The lifting rod diameter is $50 \mathrm{~mm}$, a maximum load of 1.2 tons, which are to meet the lifting requirements. Between the press ring and the lower die, between the pressure of the upper and the upper mold to set up, the clamping block spacing is $300 \sim 500 \mathrm{~mm}$, here it is set to $425 \mathrm{~mm}$. Blank holder is conducted integral casting, in order to reduce weight and casting non important part which should be emptied and binder to support bar. Rib thickness is $40 \mathrm{~mm}$, chamfer $\mathrm{C} 20$.

Design of convexmould.

As important part of forming parts, the quality of the punch directly determines the quality of the parts. In the design of the convex mold, there are several forms, which are two kinds commonly, namely: the integral and the combination type. In this design, the size of the mold is relatively large, taking in to account the convenience of the casting and processing and the combination of reason. The structure of the projection is shown in Fig. 1 :

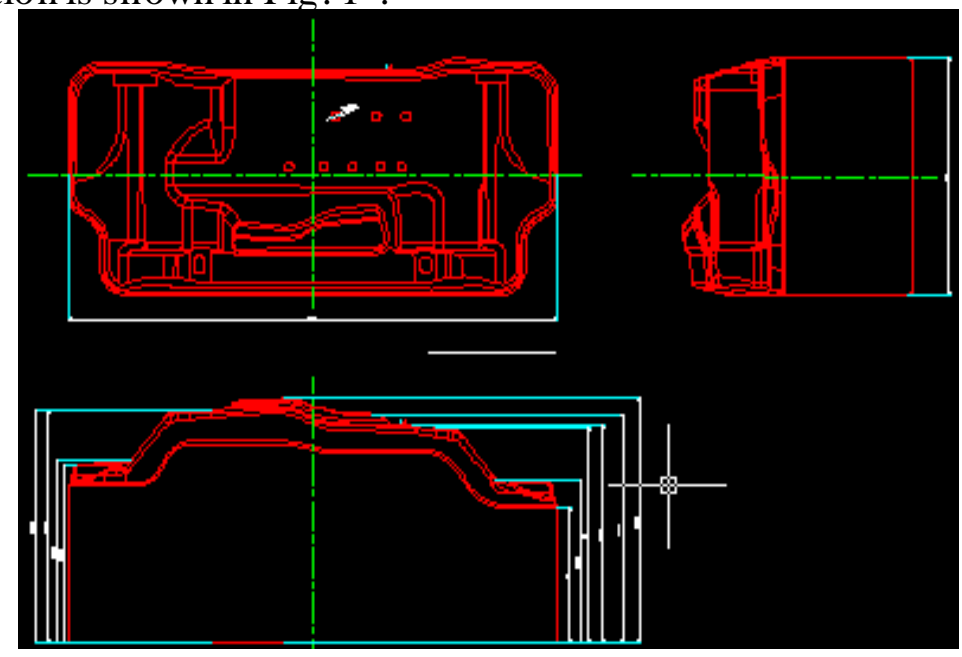

Fig. 1 pin hole avoidance

In the convex die, set up a total of eight vent diameter which is $10 \mathrm{~mm}$, setting principles do not affect the quality of parts and can smooth out parts, ventilation hole drill directly drill and dust proof hose.

Design of lower die.

Consistent edge mould seat dimensions and the pressure ring and blank holder corresponding, die holder to cast the mold closing limit bumps and Taiwan. The height is $10 \mathrm{~mm}$ and the diameter is $70 \mathrm{~mm}$, with screw M10 and closing stopper connected. Die holder is provided with a reinforcing rib, which is along the $\mathrm{X}$ direction with thickness of $40 \mathrm{~mm}$ and along the $\mathrm{Y}$ direction with the thickness of $30 \mathrm{~mm}$, 
strengthen rib design to avoid cross, T-shaped crossing is made, in order to increase the relative stiffness and stren gth. The next module structure is shown in Fig. 2 below.

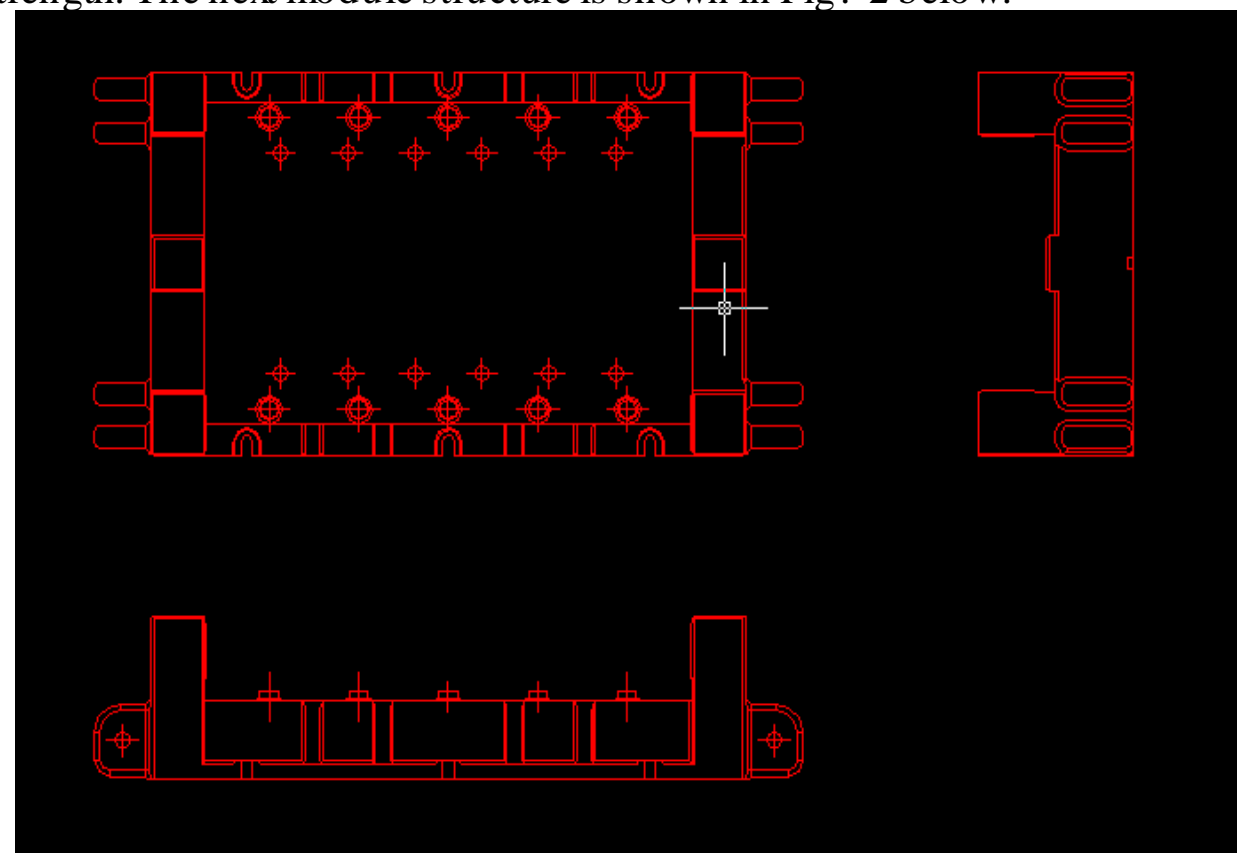

Fig. 2 Schematic diagrams of the mold structure

Design of upper mold.

The length and the width of the upper die are consistent with the lower modulus, and the upper mould block is also cast out of the balance pad block. The height is $10 \mathrm{~mm}$ and the diameter is $70 \mathrm{~mm}$. The structure of the upper mold is shown in Fig. 3 .

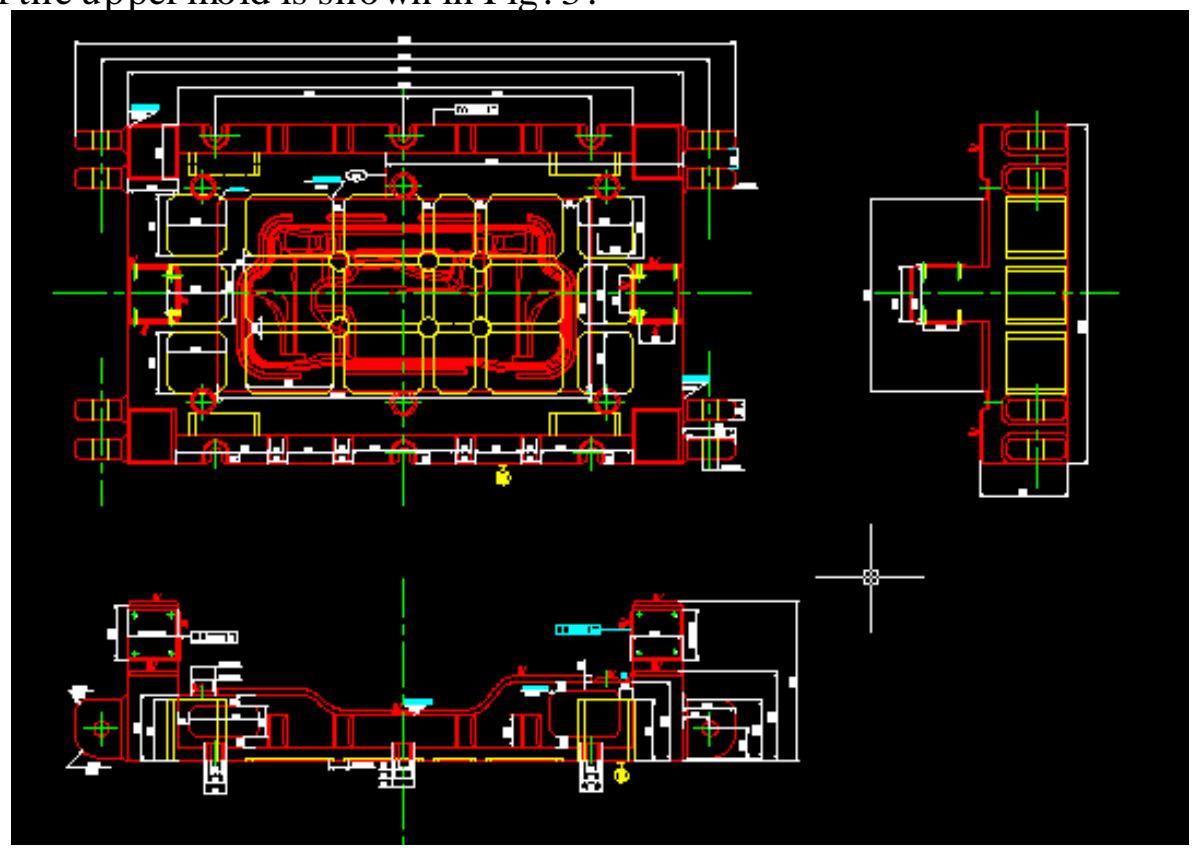

Fig. 3 The structure of the upper mold

The mold base and the mold seat ring of the mold press material circle evenly adopt HT350 material casting and become. The real mould casting technology is a new technology of the cover die manufacture.

Design of mould assistant parts. Balance pad design.

In order to make the mold into the mold uniform stress while avoiding and holder of the direct impact pressure and prevent the tilt and lead to accelerating wear of punch and die, we must balance pad blocks set between the upper die and the blank holder. HRC28-32 balance pad setting mainly 
according to the industry standard,here in the light of the standards is Fuzhen mould company design standards, due to the length of the die of $1500 \mathrm{~mm}$ which belongs to the medium-sized mold, reference standard, the diameter of the selection of the balance block is $60 \mathrm{~mm}$ and $20 \mathrm{~mm}$ high, the material is 45 .

Pad block design.

Exactly block is mainly in order to restrict to the limit position of the punch die, which can effectively prevent the die stamping distance beyond the crush punch, but also can prevent the over drawing deep drawing parts crack. When the pressure plate is to end the contact pad, it mean s that the drawing has ended. The bottom of the balance block must be in the bottom. The size of the pad block and the same as the balance block is 45 .

lifting device - lug design (Fig. 4 ).
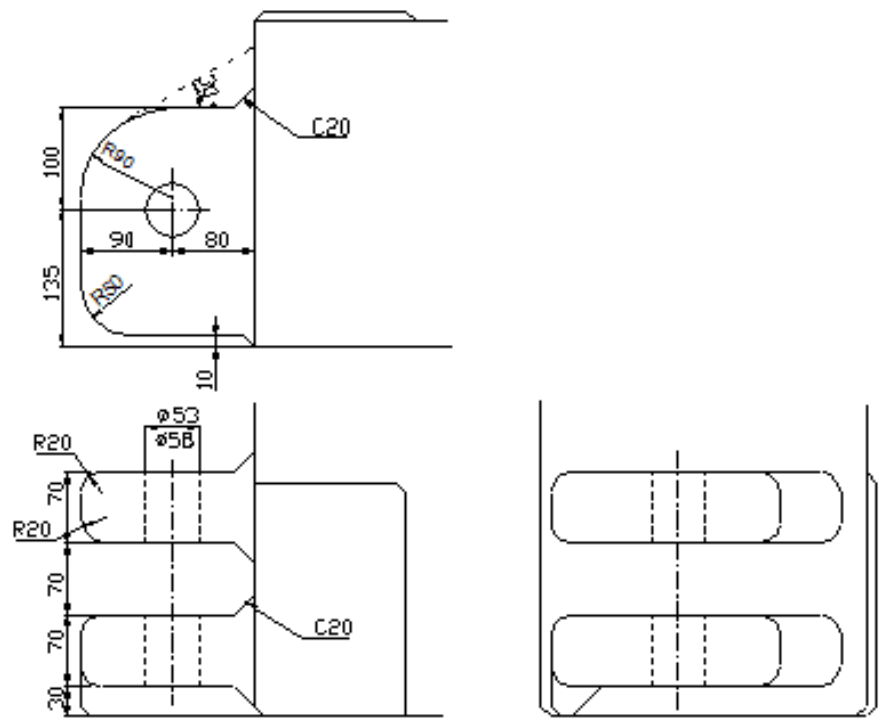

Fig. 4 hanging ear

selection of other parts.

The die design uses the wear-resistant plate as the guide device. Wear plate is now most of the standard. The design of the BMWP180 x 180 and 90 x two 90 types of wear-resistant plate, a total of 28 blocks.

\section{The working principle of the mould}

Before the mould clamping, press the cylinder pressure rim 7 through plunger will jack, the ejection height is higher than that when die closed is $40 \mathrm{~mm}$, generally higher than punch, which can ensure the smooth on the blank holder ring. Sheet metal by the operating manual workers is on the pressure surface, due to the locator at the top of slope and surface polishing, which makes the sheet metal be into a very convenient. Put away after sheet metal, 8 on the pressure of upperdie under the action of the slider declines, the upper die down first and blank holder ring 7 pressure plate, pressure rim by press plunger and blank-holder force, and the moulding pressure burden surface shape, upper die and the blank holder ring depend on wear-resistant plate 1 direction, blank holder ring under the action of balance block 6 steady downward with the upper die. Upper die down to a certain extent, it begins to contact the punch die under 1, the upper die and lower die by wearing plate 1 guide, concave die and punch work together to make sheet metal forming, on the pressure side ring and the lower die clamping spacing block contact with the drawing process. Upper die began to retum, blank holder ring under the effect of plunger upward with upper die, at this point, the artifacts are punch out, pressure rim rises to a certain height $(40 \mathrm{~mm})$ which does no longer exercise. Because this is big, the weight of the parts of its own gravity is greater than the upper die, the clamping force of the product, so the parts on the blank holder ring is by its own gravity, parts of out is very convenient. 


\section{Conclusions}

This paper introduces the design of the drawing dies design of automobile panel die of automobile covering parts forming feasibility and blanking direction analysis. According to the parts of the complex degree of surface, it determines the needs of four steps which are drawing forming parts shape, repair edge removal parts of addendum surface, flanging, punching into the final dimensions of the workpiece.

\section{References}

[1] Qijin Weng. Xincheng Xu. "stamping process and die design". Machinery Industry Press 2006.2.

[2] writing committee."modern mould technology" Design and manufacture of automobile panel perish. Beijing: National Defense Industry Press, 1998.1.

[3] Guangqi Tu. Die technology. Beijing: Machinery Industry Press, 2002.8.

[4] Fengqin Sun. Stamping and plastic pressure equipment. Beijing: Machinery Industry Press, 1997.10.

[5] Kuihua Jiang, Jing rong Xiao. "Stamping technology", machinery industry presses. 2002.8.

[6] Guoming Xie, Xueping Wang, Xiangy ang Ceng. UGNX based and Application Tutorial.Beijing: Electronics Industry Press, 2003.1.

[7] Xiaohong Wu. Technical features of Japanese stamping die. Mould technology. 2001 (1), 49 52.

[8] Xiang Ju. Analysis and Simulation of sheet metal forming for automobile body. Automotive engineering. 1996 (4), 249 256.

[9] Ying Cao. Stretch / shrink flanging process of trimming line prediction. Engineering mechanics. 2001 (4), 35 40.

[10] F.-K. Chen and Y.-C. Liao . An Analysis of Draw-Wall Wrinkling in a Stamping Die Design. Int J Adv Manuf Technol (2002) 19:253 - 259. 